\title{
Characterization of surface orientation and tenderness of sous vide processed edible offal and psoas muscle from Dohne Merino sheep
}

\author{
P.O. Fayemi ${ }^{\#}$ \& V. Muchenje \\ Department of Livestock and Pasture Science, Faculty of Science and Agriculture, University of Fort Hare, \\ Private Mail Bag X1314, Alice 5700, Eastern Cape Province, South Africa
}

(Received 24 February 2017; Accepted 24 February 2019; First published online 23 April 2019)

\author{
Copyright resides with the authors in terms of the Creative Commons Attribution 4.0 South African License. \\ See: http://creativecommons.org/licenses/by/4.0/za \\ Condition of use: The user may copy, distribute, transmit and adapt the work, but must recognize the authors and \\ the South African Journal of Animal Science.
}

\begin{abstract}
The microstructural orientation and tenderness of edible offal and the psoas minor muscle from Dohne Merino sheep were compared in this study. Following evisceration and cleaning, fresh meat samples were collected from slaughtered lambs and ewes of different age groups and thermally processed to varying degrees of doneness using sous vide apparatus. A scanning electron microscope (SEM) was used for the characterization of the surface orientation and elemental composition. The results for tenderness showed that edible offal with anisotropic orientation had higher Warner-Bratzler shear force (WBSF) values, but those with some degrees of uniformity (isotropicity) in their surface orientation were comparatively tender. The rumen and trachea from the lambs, six-tooth and eight-tooth sheep at $10-12,23-36$ and $28-48$ months old at slaughter had the highest WBSF values among all the meat samples. Our findings showed that edible offal from the lambs with isotropic orientation was more tender and richer in protein than those from ewes. Also, processing the psoas minor muscle and edible offal with sous vide at $100^{\circ} \mathrm{C}$ in the shortest cooking time of 30 minutes had the greatest effect on tenderness of the meat samples. In descending order, the psoas minor muscle, liver and tongue from the lambs were found to be inherently more proteinaceous than other meat samples. The differences observed in the tenderness and protein contents of the edible offal and the psoas muscle could be attributed to variations in the microstructural organization of the muscle fibres in Dohne Merino and to their response to thermal processing.
\end{abstract}

Keywords: anisotropy, doneness, isotropy, meat processing, Merino, scanning electron microscopy

\# Corresponding author: pfayemi@ufh.ac.za or topepeter@gmail.com

\section{Introduction}

Sheep are domesticated ruminant mammals from the order of artiodactyla. Meat-based proteins that are derivable from artiodactyl or cloven-hooved species such as sheep are commonly obtained from the striated and non-striated muscles. Usually, multinucleated skeletal (striated) muscles, smooth (non-striated) muscles and cross-linked cardiac (striated) muscles from artiodactyl species are not eaten raw, but are converted into edible by-products using any processing method to unlock the inherent nutrients and overall palatability traits (O'Quinn et al., 2018; Shen et al., 2018). The psoas muscles and edible offal are not inferior meat cuts from the pool of meat species, but repositories of nutrients with high biological value (Fayemi et al., 2018). Commonly referred to as fillet mignon or tenderloin, psoas muscles (major and minor) are colour-labile skeletal muscles, which act like hydraulic pumps for flexing and stabilizing the spines (Belskie et al., 2015; Kakarala et al., 2016). Of the psoas muscles, psoas minor is a lean fusiform muscle, which originates from the lateral surface of the 12th thoracic (T12) and 1st lumbar (L4) regions and runs ventrally through the length of the vertebral column (Protas et al., 2017). Edible offal is a generic term for non-carcass meat, which is otherwise known as the fifth quarters, variety meats, organ meats or entrails of butchered animals. Liver, heart, kidney, trachea, spleen, head, brain, pancreas, trotters, tongue, oesophagus, tail, sweetbreads and stomach lining from cattle, chickens, games, goats, pigs, and sheep are typical variety meats that are used to prepare several traditional dishes in offal cuisines (Fayemi \& Muchenje, 2012).

The famous Greek gyros, Southern American chitterlings, Turkish Arnavut Ciğeri, Kenyan mutura, and South African kerrie-afval and mala mogodu are delicacies that are often prepared from offal through 
conventional processing methods (Toldra et al., 2016; Erasmus \& Hoffman, 2017). In this study, the choice of the sous vide cooking device is based on its numerous benefits over traditional or conventional cooking methods. Sous vide is a convenient method of processing food in sealed, vacuumed and heat-stable pouches at programmable alarm of $1^{\circ}$ increments (Douglas, 2012; Pulgar et al., 2012). The hermitic seal created in sous vide bags allows heat to be transferred efficiently from the water bath to the food, trapping off-flavour that may be caused by oxidation (Garcl'a-Linares et al., 2004; Badwin, 2011). Cooking at a temperature higher than $50^{\circ} \mathrm{C}$ with a sous vide device minimises water and nutrient losses and retains the natural flavour, aroma, tenderness and other organoleptic properties. Sous vide processed products have a relatively stable shelf life (Hosahalli \& Michélc, 2006; Garcia et al., 2008). Hermetically sealed containers often inactivate undesirable enzymes and microbial toxins by hindering the activities of microorganisms that require oxygen (obligate aerobes) from causing food spoilage or health risks (Karel \& Lund, 2003; Ayadi et al., 2009). This method guarantees a cleaner working environment with minimum stress on the chef (Church \& Parsons, 2000). Despite its competitive advantages, knowledge is still limited of the association between sous vide cooking, tenderness, surface orientation and protein constituents in psoas minor muscles and edible offal from ovine species such as the Dohne Merino sheep breed.

In context, surface orientation is beneficial for describing the alignment of muscle fibre, appearance, processability and fracture behaviour of meat (Von Seggern et al., 2005). Establishing the correlation between surface orientation and tenderness or intramuscular texture is important during meat processing as it helps to determine strategically the direction of the meat cut, making carving easier at butchery (Xia et al., 2007). Scanning electron microscope (SEM) was used in this study to characterize the surface orientation and elemental composition of meat samples. SEM analysis uses a non-destructive type of electron microscope to produce images by scanning with a beam of electrons in the form of raster scan patterns (Egerton, 2005). The electrons are designed to interact with atoms in the samples to produce signals that contain information about the surface morphology (or topography) and composition of the samples. Accelerated electrons in SEM carry significant amounts of kinetic energy, which is dissipated with a range of signals from electron-sample interactions. These signals include secondary electrons that produce SEM images and diffracted backscattered electrons for understanding the elemental composition and fibre orientation of samples. SEM micrographs produce magnification in the range of six order magnitude from 10 to 500000 times (Anderhalt, 2007). Dohne Merino was chosen as one of the highly prized composite ovine species in southern Africa (Swanepoel et al., 2004; Cloete et al., 2008; Fayemi \& Muchenje, 2018). There is no evidence of a relationship between fibre orientation, sous vide cooking and tenderness of edible offal and psoas minor muscle from this ovine species.

The objective of the study was to characterize the surface orientation and determine the effect of sous vide cooking on the tenderness of edible offal and psoas minor muscles from Dohne Merino ewes and lambs.

\section{Materials and Methods}

This study was conducted in compliance with the institutional guidelines by the Research Ethics Committee of the University of Fort Hare (UFH/UREC, 7-REC-270710-028), South Africa. A general chronological guide, known as the tooth-cementum method, was used to estimate the age groups of the sheep (AGFACTS, 2003). One hundred and thirty-eight sheep were used, consisting of ewes $(n=69)$ and lambs $(n=69)$. The cementum method was used by grouping the animals as lambs, six-tooth sheep and eight-tooth sheep aged $10-12$ months $(n=46), 23-36$ months $(n=46)$ and $28-48$ months $(n=46)$, respectively. Fresh meat samples (psoas muscle and edible offal) were collected from a high-throughput abattoir from 1 to 30 minutes after slaughter. A range of $20-40 \mathrm{~g}$ of the psoas minor muscle, liver, lung, heart, rumen, kidney, abomasum, rumen, omasum, reticulum, oesophagus, tongue, spleen, small intestine, and large intestine was excised from the slaughtered ewes and lambs. The excised meat samples were replicated or sub-divided into three cooking groups, namely rare, medium rare and well done. The samples were then vacuum sealed in plastic bags and submerged in a temperature-controlled water bath for cooking. Samples for the rare group were held in the sous vide device at $75^{\circ} \mathrm{C}$ for 60 minutes, those in the medium rare at $88^{\circ} \mathrm{C}$ for 45 minutes and the well-done group, at $100{ }^{\circ} \mathrm{C}$ for 30 minutes, respectively. The minimum cooking regime of $75^{\circ} \mathrm{C}$ was adopted based on the recommendations by the Thermal Centre for Doneness of Meat of the American Meat Science Association (1995). To determine tenderness, meat samples were first cooled after cooking for an average of 10 minutes at room temperature. Sub-samples measuring 10 - 15 $\mathrm{mm}$ diameter were cored from the samples, particularly the psoas muscle and liver. Coring was done parallel to the grain of samples and sheared perpendicularly to the fibre direction using a Warner-Bratzler shear force (WBSF) device mounted on an Instron ${ }^{\circledR}$ electromechanical universal testing machine (3300-5900, crosshead speed $400 \mathrm{~mm} /$ minute, one shear in the centre of each core). A sharp scalpel was used to obtain 
an approximate $10-15 \mathrm{~mm}$ size, which could not be cored with the WBSF device. Three replicate measurements were taken from each meat sample for the WBSF test.

With minor modifications, the procedures by Bozzola \& Russel (1999) and Hayat (2000) were followed. The dehydration of samples for SEM was done by excising $\leq 5 \mathrm{~g}$ portions from each meat sample and fixing them in $10 \%$ formalin solution to ensure that the tissue ultrastructure remained intact prior to analysis. After the first fixation, the samples were re-fixed in $2.5 \%$ sodium cacodylate buffer glutaraldehyde $(\mathrm{pH} 7.2)$ at $4{ }^{\circ} \mathrm{C}$ for 2 hours and post-fixed again with $1 \%$ sodium cacodylate buffer uranyl acetate for 120 minutes. Afterwards, distilled water was used to rinse the samples as a transitional solvent to prevent shrinkage of the sample in the process of dehydration in ethanol. Sequentially, each sample was held for 20 minutes in ethanol in ascending grades of $10 \%, 20 \%, 30 \%, 40 \%, 50 \%, 60 \%, 70 \%, 80 \%, 90 \%$ to $100 \%$ during dehydration. A thin film of gold palladium was used for sputter coating to enhance X-ray microanalysis and improve electrical conductivity of the sample surface through SEM. Sputter coating and critical point drying of samples then followed, using the Hitachi critical point dryer HCP-2 (Hitachi Koki Co., Ltd., Tokyo Japan) to prevent the samples from distorting and to boost structural preservation. This was done by mounting the samples on aluminium stubs with double-sided carbon tape followed by sputter coating with gold palladium (Au-Pb) using the Eiko IB.3 ion coater (EIKO Engineering Co., Ltd., Japan). For highresolution images of edible offal and psoas minor muscles with sufficient contrast, a conductive coating was used to suppress surface charging, minimize radiation damage, and increase electron emission from the surface. The samples were finally observed under the SEM (JEOL JSM-6390LV) to determine surface micrographs and orientations. The elemental constituents of the samples were auto-generated by the Energy Dispersive X-Ray Spectroscopy of SEM. The crude protein (CP) value from each sample was obtained as derivatives of $\mathrm{N}$-values using the equation:

Crude protein $(\mathrm{CP})=[\mathrm{N} \times 6.25] \%$.

Data were analysed using the PROC GLM procedures of SAS (version 9.1.3 of 2007). Significant differences were determined at $P<0.05$.

\section{Results}

The effects of sous vide cooking on the WBSF values of the intestinal offal from Dohne Merino sheep of various age groups are presented in Table 1 . The results showed clearly that there was limited variation in WBSF values in the meat samples. There were no significant differences $(P>0.05)$ in the tenderness of the abomasum and rumen across the three age groups, except for marginal numerical variations in their WBSF values. Although the WBSF values for the reticulum were higher $(P<0.05)$ compared with the values obtained from the large intestine and small intestine, the tenderness of these organs followed a similar pattern across age groups. The results imply that the reticulum, large intestine and small intestine of the lambs were more tender than those from the older sheep, which belonged to six-tooth and eight-tooth age groups. The uniqueness in the thickness of the omasal leaves for lambs, six-tooth and eight-tooth sheep contributed to the results obtained for the tenderness of the omasum in this study. The tenderness of all the intestinal offal consistently followed a similar pattern to those in the rare regimen group, which recorded the highest WBSF values. This implies that cooking the intestinal organs at a temperature of $100{ }^{\circ} \mathrm{C}$ for 30 minutes produced the most tender meat.

Sous vide processing had a significant effect on the tenderness of only four (of the nine) samples of the non-intestinal offal (Table 2). The tenderness of the psoas minor muscle, kidney, liver, lung and oesophagus followed a similar pattern because there were no differences $(P>0.05)$ among samples from the lambs, six-tooth and eight-tooth sheep. The results showed that the tenderness of the heart, trachea, tongue and spleen was significantly $(P<0.05)$ influenced by age group. In comparison with the younger sheep, higher WBSF values $(P<0.05)$ recorded from the trachea, tongue and spleen showed that the muscle of eight-tooth sheep was tougher. As expected, the presence of tough cartilaginous rings in the trachea of the ewes contributed significantly $(P<0.05)$ to the highest WBSF values, meaning that the trachea was tougher than other meat samples. The WBSF values for sheep at $10-12$ months and $23-36$ months old were statistically similar. It can thus be deduced that more mechanical force was expended on the non-intestinal samples, which had comparatively higher WBSF values, to cut through their fibres and cartilage during shearing. A general observation on the cooking regimens showed that most of the non-intestinal offal responded in a similar way to intestinal samples under the rare, medium rare and well-done degrees of doneness. 
Table 1 Least square means ( \pm SE) for effect of sous vide cooking on Warner-Bratzler shear force values of intestinal offal from Dohne Merino of different age groups

\begin{tabular}{|c|c|c|c|c|c|c|}
\hline \multirow{2}{*}{ Meat samples } & \multicolumn{3}{|c|}{ Age (months) } & \multicolumn{3}{|c|}{ Degrees of doneness } \\
\hline & $10-12$ & $23-36$ & $28-48$ & Rare $^{1}$ & Medium rare ${ }^{2}$ & Well done ${ }^{3}$ \\
\hline Abomasum & $37.4 \pm 1.43$ & $39.9 \pm 2.27$ & $41.2 \pm 3.21$ & $68.8^{\mathrm{a}} \pm 2.04$ & $48.3^{b} \pm 2.17$ & $33.3^{\mathrm{c}} \pm 2.17$ \\
\hline Large intestine & $43.4^{b} \pm 1.49$ & $52.3^{a} \pm 2.37$ & $51.9^{a} \pm 3.35$ & $69.2^{a} \pm 2.13$ & $46.1^{b} \pm 2.26$ & $32.4^{\mathrm{C}} \pm 2.26$ \\
\hline Omasum & $56.4^{a} \pm 2.06$ & $57.9^{a} \pm 3.25$ & $52.2^{b} \pm 4.60$ & $85.3^{\mathrm{a}} \pm 2.93$ & $53.3^{b} \pm 3.11$ & $27.9^{c} \pm 3.11$ \\
\hline Reticulum & $52.6^{b} \pm 2.09$ & $60.3^{a} \pm 3.32$ & $57.3^{a} \pm 4.69$ & $91.9^{\mathrm{a}} \pm 2.98$ & $49.5^{b} \pm 3.17$ & $28.7^{\mathrm{C}} \pm 3.17$ \\
\hline Rumen & $59.3 \pm 1.59$ & $59.6 \pm 2.24$ & $61.5 \pm 1.00$ & $80.4^{\mathrm{a}} \pm 1.43$ & $60.6^{b} \pm 1.52$ & $39.5^{c} \pm 1.52$ \\
\hline Small intestine & $37.4^{\mathrm{b}} \pm 2.22$ & $43.3^{a} \pm 3.52$ & $45.4^{a} \pm 4.98$ & $66.2^{\mathrm{a}} \pm 3.17$ & $42.3^{b} \pm 3.36$ & $17.6^{\mathrm{C}} \pm 3.36$ \\
\hline
\end{tabular}

${ }^{\mathrm{a}, \mathrm{b}, \mathrm{c}}$ Means in the same row with different superscripts were significantly different $(P<0.05)$

${ }^{1}$ Cooked at $75^{\circ} \mathrm{C}$ for 60 minutes; ${ }^{2}$ cooked at $88^{\circ} \mathrm{C}$ for 45 minutes and ${ }^{3}$ cooked at $100^{\circ} \mathrm{C}$ for 30 minutes

Table 2 Least square means $( \pm S E)$ for effect of sous vide cooking on Warner-Bratzler shear force values of psoas minor muscle and non-intestinal offal from Dohne Merino of different age groups

\begin{tabular}{|c|c|c|c|c|c|c|}
\hline \multirow{2}{*}{ Meat samples } & \multicolumn{3}{|c|}{ Age (months) } & \multicolumn{3}{|c|}{ Degrees of doneness } \\
\hline & $10-12$ & $23-36$ & $28-48$ & Rare $^{1}$ & Medium rare $^{2}$ & Well done ${ }^{3}$ \\
\hline Psoas minor & $30.1 \pm 1.27$ & $30.6 \pm 2.01$ & $29.9 \pm 2.84$ & $46.9^{\mathrm{a}} \pm 1.81$ & $25.6^{\mathbf{b}} \pm 1.92$ & $18.0^{C} \pm 1.92$ \\
\hline Heart & $27.8^{\mathrm{a}} \pm 1.63$ & $21.9^{b} \pm 2.6$ & $19.8^{\mathbf{b}} \pm 3.64$ & $29.4^{\mathrm{a}} \pm 2.32$ & $27.7^{\mathbf{b}} \pm 2.46$ & $12.5^{b} \pm 2.46^{b}$ \\
\hline Kidney & $18.2 \pm 0.45$ & $17.9 \pm 0.71$ & $17.9 \pm 1.00$ & $24.9^{a} \pm 0.64$ & $16.9^{b} \pm 0.68$ & $12.4^{C} \pm 0.68^{C}$ \\
\hline Liver & $16.7 \pm 0.68$ & $16.2 \pm 1.08$ & $15.8 \pm 1.53$ & $29.4^{a} \pm 0.97$ & $12 .^{b} \pm 1.03$ & $6.6^{c} \pm 1.03^{c}$ \\
\hline Lung & $21.3 \pm 0.84$ & $19.6 \pm 1.33$ & $19.6 \pm 1.88$ & $30.9^{a} \pm 1.19$ & $19.3^{b} \pm 1.27$ & $10.3^{c} \pm 1.27^{c}$ \\
\hline Oesophagus & $92.1 \pm 3.40$ & $93.9 \pm 5.38$ & $96.2 \pm 7.61$ & $133.1^{\mathrm{a}} \pm 4.85$ & $98.4^{\mathrm{b}} \pm 5.14$ & $50.6^{c} \pm 5.14^{c}$ \\
\hline Spleen & $24.7^{\mathbf{b}} \pm 0.91$ & $24.7^{b} \pm 1.45$ & $27.4^{a} \pm 2.04$ & $36.8^{a} \pm 1.30$ & $24.3^{b} \pm 1.38$ & $15.6^{c} \pm 1.38^{c}$ \\
\hline Tongue & $41.78^{c} \pm 2.04$ & $46.2^{b} \pm 3.22$ & $50.5^{a} \pm 4.55$ & $61.7^{\mathrm{a}} \pm 2.89$ & $52.0^{b} \pm 3.08$ & $24.8^{c} \pm 3.08^{c}$ \\
\hline Trachea & $92.4^{b} \pm 2.64$ & $104.2^{\mathrm{a}} \pm 4.17^{\mathrm{a}}$ & $103.4^{\mathrm{a}} \pm 5.90$ & $133.1^{\mathrm{a}} \pm 4.85$ & $98.4^{b} \pm 5.14$ & $50.6^{c} \pm 5.14^{c}$ \\
\hline
\end{tabular}

a, b, c Means in the same row with different superscripts were significantly different $(P<0.05)$

${ }^{1}$ Cooked at $75^{\circ} \mathrm{C}$ for 60 minutes; ${ }^{2}$ cooked at $88^{\circ} \mathrm{C}$ for 45 minutes; and ${ }^{3}$ cooked at $100^{\circ} \mathrm{C}$ for 30 minutes 
Similar inferences can be drawn that cooking methods for intestinal offal are applicable to the non-intestinal meat samples. Meat samples that were cooked under the highest temperature of $100{ }^{\circ} \mathrm{C}$ for the shortest duration of 30 minutes had the lowest WBSF values and thus produced the most tender meats.

Except for the reticulum, WBSF values for most of the intestinal offal from ewes were higher $(P<0.05)$ than those from male lambs (Table 3 ). The results suggest that most of the intestinal samples from lambs were tender and thus required less WBSF for shearing after cooking. However, the WBSF values for the reticulum from lambs and ewes did not differ $(P>0.05)$. Non-intestinal meat from the lambs was found to have lower WBSF values than that from the ewes. The results also showed that the psoas minor muscles from the lambs were more tender $(P<0.05)$ than those from the ewes. Comparing the tenderness of meat samples under various cooking regimens, meat that was cooked at $75^{\circ} \mathrm{C}$ for 60 minutes had the highest WBSF values, indicating that the rare group produced the toughest meat. The effect of cooking regimen was significant $(P<0.05)$ for most of the non-intestinal meat, except for the kidney $(P>0.05)$ (Table 4). The effect of cooking regimen on non-intestinal meat followed a similar pattern to the intestinal meat (Table 3 ). Intrinsically, the trachea from ewes had the highest WBSF values $(P<0.05)$ owing to the presence of tough and insoluble cartilaginous rings. All the meat samples in the rare group had the highest $(P<0.05)$ WBSF values and those in the well-done group $(P<0.05)$ had the lowest WBSF values. It could be deduced that organ meat that was cooked at a relatively lower temperature for longer produces tougher meat and vice versa.

Table 3 Least square means ( \pm SE) for effect of sous vide cooking on Warner-Bratzler shear force values of intestinal edible offal from Dohne Merino of different classes

\begin{tabular}{|c|c|c|c|c|c|}
\hline \multirow{2}{*}{ Meat samples } & \multicolumn{2}{|c|}{ Sheep classes } & \multicolumn{3}{|c|}{ Degrees of doneness } \\
\hline & Ewes & Lambs & Rare $^{1}$ & Medium rare ${ }^{2}$ & Well done ${ }^{3}$ \\
\hline Abomasum & $57.9^{\mathrm{a}} \pm 2.19$ & $40.9^{b} \pm 1.55$ & $62.1^{\mathrm{a}} \pm 1.81$ & $48.6^{b} \pm 2.01$ & $33.9^{c} \pm 2.04$ \\
\hline Large intestine & $49.8^{\mathrm{a}} \pm 1.85$ & $30.5^{b} \pm 1.31$ & $66.2^{\mathrm{a}} \pm 2.02$ & $43.8^{\mathrm{b}} \pm 2.25$ & $30.2^{c} \pm 2.29$ \\
\hline Omasum & $49.7^{a} \pm 3.68$ & $44.2^{b} \pm 3.68$ & $64.0^{\mathrm{a}} \pm 1.82$ & $54.1^{b} \pm 2.91$ & $28.4^{\mathrm{C}} \pm 2.96$ \\
\hline Reticulum & $59.1^{\mathrm{a}} \pm 4.32$ & $56.2 \pm 3.06$ & $86.1^{\mathrm{a}} \pm 2.62$ & $83.2^{\mathrm{a}} \pm 1.30$ & $48.1^{\mathrm{c}} \pm 1.94$ \\
\hline Rumen & $62.8^{\mathrm{a}} \pm .55$ & $57.6^{\mathrm{b}} \pm 1.81$ & $81.0^{a} \pm 1.28$ & $61.2^{\mathrm{b}} \pm 1.42$ & $40.1^{c} \pm 1.44$ \\
\hline Small intestine & $45.3^{a} \pm 2.26$ & $15.8^{b} \pm 1.59$ & $63.7^{\mathrm{a}} \pm 2.86$ & $40.2^{b} \pm 3.18$ & $16.0^{c} \pm 3.23$ \\
\hline
\end{tabular}

a, b, c Means in the same row with different superscripts were significantly different $(P<0.05)$;

${ }^{1}$ Cooked at $75^{\circ} \mathrm{C}$ for 60 minutes; ${ }^{2}$ cooked at $88^{\circ} \mathrm{C}$ for 45 minutes; and ${ }^{3}$ cooked at $100^{\circ} \mathrm{C}$ for 30 minutes

Table 4 Least square means $( \pm S E)$ for effect of sous vide cooking method on Warner-Bratzler shear force values of psoas minor and edible offal from Dohne Merino of different classes

\begin{tabular}{|c|c|c|c|c|c|}
\hline \multirow{2}{*}{ Meat samples } & \multicolumn{2}{|c|}{ Sheep classes } & \multicolumn{3}{|c|}{ Degrees of doneness } \\
\hline & Ewes & Lambs & Rare $^{1}$ & Medium rare ${ }^{2}$ & Well done $^{3}$ \\
\hline Psoas minor & $34.2^{\mathrm{a}} \pm 1.87$ & $23.4^{\mathrm{b}} \pm 1.32$ & $46.9^{a} \pm 1.61$ & $25.6^{b} \pm 1.79$ & $17.9^{C} \pm 1.82$ \\
\hline Heart & $33.2^{\mathrm{a}} \pm 1.80$ & $18.7^{b} \pm 1.27$ & $31.9^{\mathrm{a}} \pm 2.13$ & $29.7^{\mathrm{a}} \pm 2.36$ & $14.7^{b} \pm 2.40$ \\
\hline Kidney & $18.1 \pm 0.96$ & $18.7 \pm 0.68$ & $24.9^{a} \pm 0.56$ & $16.9^{b} \pm 0.63$ & $12.5^{c} \pm 0.64$ \\
\hline Liver & $18.5^{\mathrm{a}} \pm 1.33$ & $13.4^{b} \pm 0.94$ & $29.7^{a} \pm 0.86$ & $12.9^{b} \pm 0.96$ & $6.7^{c} \pm 0.98$ \\
\hline Lung & $25.5^{\mathrm{a}} \pm 1.23$ & $15.6^{b} \pm 0.87$ & $31.5^{\mathrm{a}} \pm 1.07$ & $19.8^{\mathrm{b}} \pm 1.19$ & $10.8^{c} \pm 1.21$ \\
\hline Oesophagus & $104.0^{\mathrm{a}} \pm .78$ & $73.7^{b} \pm 4.09$ & $132.0^{\mathrm{a}} \pm 4.31$ & $61.1^{b} \pm 1.42$ & $40.1^{\mathrm{C}} \pm 1.44$ \\
\hline Spleen & $27.4^{\mathrm{a}} \pm 1.59$ & $22.5^{\mathrm{b}} \pm 1.12$ & $36.2^{a} \pm 1.16$ & $23.8^{\mathrm{b}} \pm 1.29$ & $15.2^{c} \pm 1.32$ \\
\hline Tongue & $35.0^{\mathrm{a}} \pm 3.05$ & $46.8^{\mathrm{b}} \pm 2.16$ & $59.8^{\mathrm{a}} \pm 2.15$ & $48.5^{b} \pm 2.29$ & $21.7^{c} \pm 2.32$ \\
\hline Trachea & $114.7^{\mathrm{a}} \pm 4.63$ & $69.3^{b} \pm 3.28$ & $135.2^{\mathrm{a}} \pm .55$ & $108.1^{b} \pm 3.77$ & $53.9^{c} \pm 3.82$ \\
\hline
\end{tabular}

a, b, c Means in the same row with different superscripts were significantly different $(P<0.05)$;

${ }^{1}$ Cooked at $75^{\circ} \mathrm{C}$ for 60 minutes; ${ }^{2}$ cooked at $88^{\circ} \mathrm{C}$ for 45 minutes; and ${ }^{3}$ cooked at $100^{\circ} \mathrm{C}$ for 30 minutes 
The distinctiveness and heterogeneity of surface orientations of various meat samples from psoas minor muscles and edible offal were revealed through the SEM. Two contrasting groups of surface orientations (namely, isotropic and anisotropic) were detected among the samples (Table 5). Meat samples from ewes and lambs have varied orientations, as shown by scanning electron micrographs. Evidently, most structures are not isotropic in their surface orientation. While the physical and mechanical properties of meat samples with isotropic orientation exhibit uniform features or equality in directions, those that display anisotropic orientation were directionally dependent or manifested inequality in their properties along different axes. Although most of the samples exhibited anisotropic orientation, only the psoas minor, mouth muscle, reticulum and lung showed isotropic orientation. Typical anisotropic micrographs from the kidney and liver of Dohne Merino sheep are presented in Figure 1. Micrographs (Figures 2A and 2B) suggested that the shapes of meat samples with isotropic orientation could be circular or longitudinal. While the mouth muscle showed a unipennate longitudinal isotropic orientation, the lung exhibited a circular isotropic orientation. The mouth muscle recorded the longest fibre length of $201.2 \pm 0.54 \mu \mathrm{m}$ among the scanned nonintestinal samples (Table 6). Except for minimal numerical variations, the fibre lengths of the reticulum, spleen and mouth muscle from the lambs and ewes were not significantly $(P>0.05)$ different. In comparison with other samples, the lungs from the lambs recorded maximum $(P<0.05)$ fibre thickness of $73.0 \pm 0.90 \mu \mathrm{m}$. The fibre thickness of the spleen and kidneys from lambs and ewes did not vary significantly $(P>0.05)$.

Table 5 Surface orientation of psoas minor muscle and edible offal from Dohne Merino sheep

\begin{tabular}{lll}
\hline Meat samples & Type of orientation & Description \\
\hline Psoas minor & Isotropy & Skeletal fusiform muscle \\
Abomasum & Anisotropy & Intestinal, white offal \\
Large intestine & Anisotropy & Intestinal, white offal \\
Omasum & Anisotropy & Intestinal, white offal \\
Reticulum & Isotropy & Intestinal, white offal \\
Rumen & Anisotropy & Intestinal, white offal \\
Small intestine & Anisotropy & Intestinal, white offal \\
Heart & Anisotropy & Non-intestinal, red offal \\
Kidney & Anisotropy & Non-intestinal, red offal \\
Liver & Anisotropy & Non-intestinal, red offal \\
Lung & Isotropy & Non-intestinal, red offal \\
Mouth muscle & Isotropy & Non-intestinal, red offal \\
Oesophagus & Anisotropy & Non-intestinal, red offal \\
Spleen & Anisotropy & Non-intestinal, red offal \\
Tongue & Anisotropy & Non-intestinal, white offal \\
Trachea & Anisotropy & Non-intestinal, white offal \\
& & \\
\hline
\end{tabular}

*Characterization is based on the morphology of each sample under SEM

Overlapping levels of protein were observed from all the meat samples (Figure 3). The intestinal and non-intestinal samples from ewes and lambs had various levels of nitrogen, cadmium, aluminium, arsenic, sodium, silicon and copper. The CP values were obtained by multiplying the $\mathrm{N}$-value by 6.25 . With the exception of the large intestine, as depicted by percentage of $\mathrm{CP}$ content, nitrogen $(\mathrm{N})$ contents in samples from the lambs were higher $(P<0.05)$ than those from the ewes. Among the intestinal offal, the highest amount of $\mathrm{N}$ was found in the rumen from the lambs. This amount was also responsible for the highest CP $(P$ $<0.05)$ level obtained from the rumen. The lowest $\mathrm{N}$ levels in the abomasum of ewes obviously account for the lowest amounts of CP $(27.6 \pm 0.09)$ in the same organ. Also, $\mathrm{N}$ levels in most of the non-intestinal offal from the lambs were higher than those from the ewes. The psoas minor had the highest $(P<0.05) \mathrm{N}$ contents among the non-intestinal offal which invariably agrees with the highest CP value (Figure 3 ). Incidentally, the protein contents in the intestinal offal were found to be significantly higher $(P<0.05)$ than those in the non-intestinal ones. 


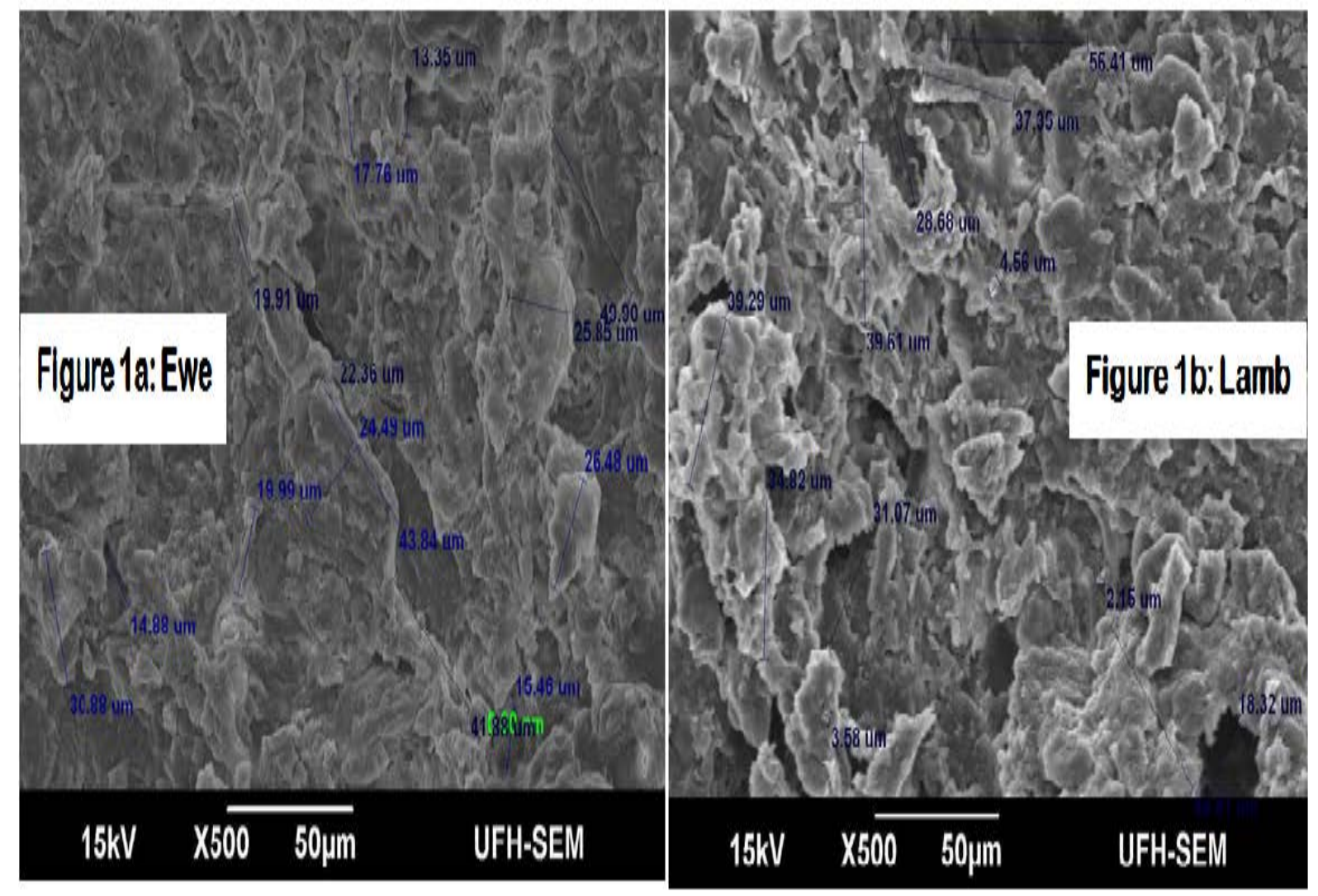

Figure 1 Typical anisotropic micrographs from the kidney a) and liver b) of Dohne Merino sheep 


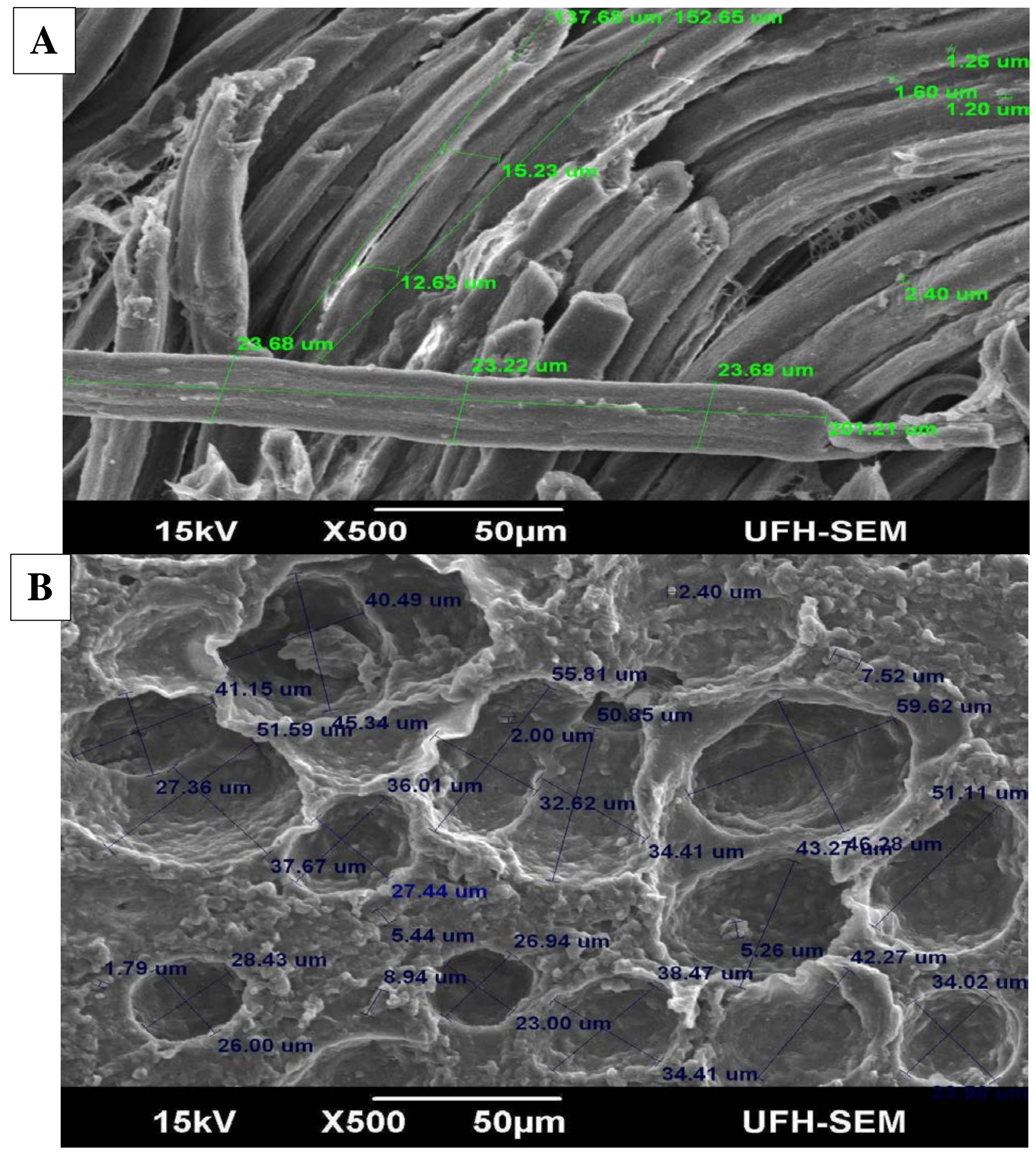

Figure 2 Typical circular and longitudinal isotropic micrographs of the lung A) and mouth muscle B) from Dohne Merino sheep 
Table 6 Comparison of fibre length and fibre thickness of psoas minor and edible offal from Dohne Merino sheep

\begin{tabular}{|c|c|c|c|c|}
\hline \multirow{2}{*}{ Meat samples } & \multicolumn{2}{|c|}{ Fibre length $(\mu \mathrm{m})$} & \multicolumn{2}{|c|}{ Fibre width $(\mu \mathrm{m})$} \\
\hline & Lamb & Ewe & Lamb & Ewe \\
\hline & \multicolumn{4}{|c|}{ Intestinal offal } \\
\hline Abomasum & $63.9^{\mathrm{a}} \pm 0.12$ & $54.2^{b} \pm 0.17$ & $4.6^{b} \pm 0.09$ & $5.8^{\mathrm{a}} \pm 0.48$ \\
\hline Large intestine & $80.3^{a} \pm 0.11$ & $74.1^{b} \pm 0.08$ & $8.8^{a} \pm 0.72$ & $6.7^{b} \pm 0.54$ \\
\hline Omasum & $88.0^{\mathrm{b}} \pm 0.17$ & $99.5^{a} \pm 0.19$ & $8.9^{b} \pm 0.51$ & $21.1^{\mathrm{a}} \pm 0.36$ \\
\hline Reticulum & $42.1 \pm 0.16$ & $40.4 \pm 0.18$ & $17.7^{\mathrm{b}} \pm 0.60$ & $22.4^{\mathrm{a}} \pm 0.84$ \\
\hline Rumen & $76.4^{a} \pm 0.26$ & $67.2^{\mathrm{b}} \pm 0.22$ & $24.2^{\mathrm{a}} \pm 0.78$ & $18.6^{b} \pm 0.60$ \\
\hline Small intestine & $54.2^{\mathrm{b}} \pm 0.12$ & $112.3^{\mathrm{a}} \pm 0.31$ & $23.0^{\mathrm{b}} \pm 0.36$ & $40.2^{\mathrm{a}} \pm 0.84$ \\
\hline \multicolumn{5}{|c|}{ Psoas minor and non-intestinal offal } \\
\hline Psoas minor & $86.8^{\mathrm{a}} \pm 0.55$ & $81.7^{b} \pm 0.20$ & $24.2^{\mathrm{a}} \pm 0.89$ & $18.7^{\mathrm{b}} \pm 0.77$ \\
\hline Lung & $134.7^{\mathrm{a}} \pm 0.25$ & $59.6^{\mathrm{b}} \pm 0.16$ & $73.0^{\mathrm{a}} \pm 0.90$ & $46.3^{b} \pm 0.24$ \\
\hline Spleen & $46.0 \pm 0.14$ & $44.2 \pm 0.16$ & $13.5 \pm 0.48$ & $13.4 \pm 0.48$ \\
\hline Heart & $48.0^{b} \pm 0.28$ & $55.4^{\mathrm{a}} \pm 0.64$ & $11.4^{b} \pm 0.36$ & $22.4^{\mathrm{a}} \pm 0.84$ \\
\hline Liver & $43.9^{a} \pm 0.12$ & $38.8^{a} \pm 0.12$ & $9.1^{b} \pm 0.72$ & $21.0^{a} \pm 1.08$ \\
\hline Trachea & $16.2^{\mathrm{a}} \pm 0.14$ & $13.4^{\mathrm{b}} \pm 0.17$ & $5.1^{a} \pm 0.36$ & $3.8^{b} \pm 0.24$ \\
\hline Mouth muscle & $201.2 \pm 0.54$ & $198.0 \pm 0.39$ & $23.5^{a} \pm 1.08$ & $18.9^{b} \pm 0.84$ \\
\hline Tongue & $91.1^{\mathrm{b}} \pm 0.28$ & $111.7^{\mathrm{a}} \pm 0.81$ & $10.4^{\mathrm{b}} \pm 0.41$ & $14.7^{\mathrm{a}} \pm 0.58$ \\
\hline Kidney & $38.2^{\mathrm{a}} \pm 0.33$ & $26.2^{\mathrm{b}} \pm 0.22$ & $26.0 \pm 0.64$ & $26.2 \pm 0.64$ \\
\hline Oesophagus & $49.2^{\mathrm{b}} \pm 0.12$ & $82.3^{a} \pm 0.31$ & $23.0^{\mathrm{b}} \pm 0.36$ & $34.2^{a} \pm 0.84$ \\
\hline
\end{tabular}

${ }^{\mathrm{a}, \mathrm{b}}$ Values in the same row with different superscripts were significant $(P<0.05)$

\section{Discussion}

This study demonstrated that the sous vide method had varying effects on the tenderness of edible offal and psoas minor muscles under various cooking temperatures and durations. The intrinsic heat transfer and textural properties or mechanical behaviours of meat samples were influenced by the time-temperature dependent nature of the three cooking groups.. Significantly high WBSF values from some meat samples were consistence with previous findings on skeletal muscle where greater shearing force was required to shear the skeletal muscle of ovine species (Hopkins et al., 2007; Walsh et al., 2010). Except for marginal differences, the WBSF values obtained from the psoas minor muscle of ewes $(34.2 \pm 1.87)$ from the Dhone Merino were similar to those obtained from the musculus longissimus thoracis et lumborum (33.9) and semimembranosus (34.9) of castrated Tanzanian long fat-tailed sheep (Shirima et al., 2013). Higher WBSF values from most of the samples from ewes could be attributed to the presence of a strong adhesive force in the connective tissues, low water-holding capacity, and an increase in cooking loss (Warner et al., 2007; Hong et al., 2015). However, Purslow (2005) found that strong connective bonds in the muscles of older animals could impose higher resistance to denaturation of collagen during cooking. In contrast with the samples from the ewes, the weak structural linkage of the muscle fibres, collagen content and cellular matrix in the lambs might have contributed to their relative tenderness (Jeremiah et al., 1999). As the cooking temperature rose above $160^{\circ} \mathrm{F}\left(71.11^{\circ} \mathrm{C}\right)$, the processes involved in dissolving the connective tissue collagen into gelatine were hastened. This accelerated the rate of gelatinization with the rise in cooking temperature and duration (Chiavaro et al., 2009). Therefore, muscle fibres that had been held tightly together were tenderized and began to spread apart easily to produce succulent meat.

This phenomenon explains the reason that most meat samples cooked at $100{ }^{\circ} \mathrm{C}$ for 30 minutes produced the most tender meat. It also agrees with a previous study in which skeletal meat that was cooked at a higher temperature for a shorter period produced the most tender meat (Combes et al., 2003). By extension, the severity of the heat treatment is minimized and the quality of the food is improved under the aseptic processing conditions of high temperature and short time. Despite the disparity in slaughter age of 

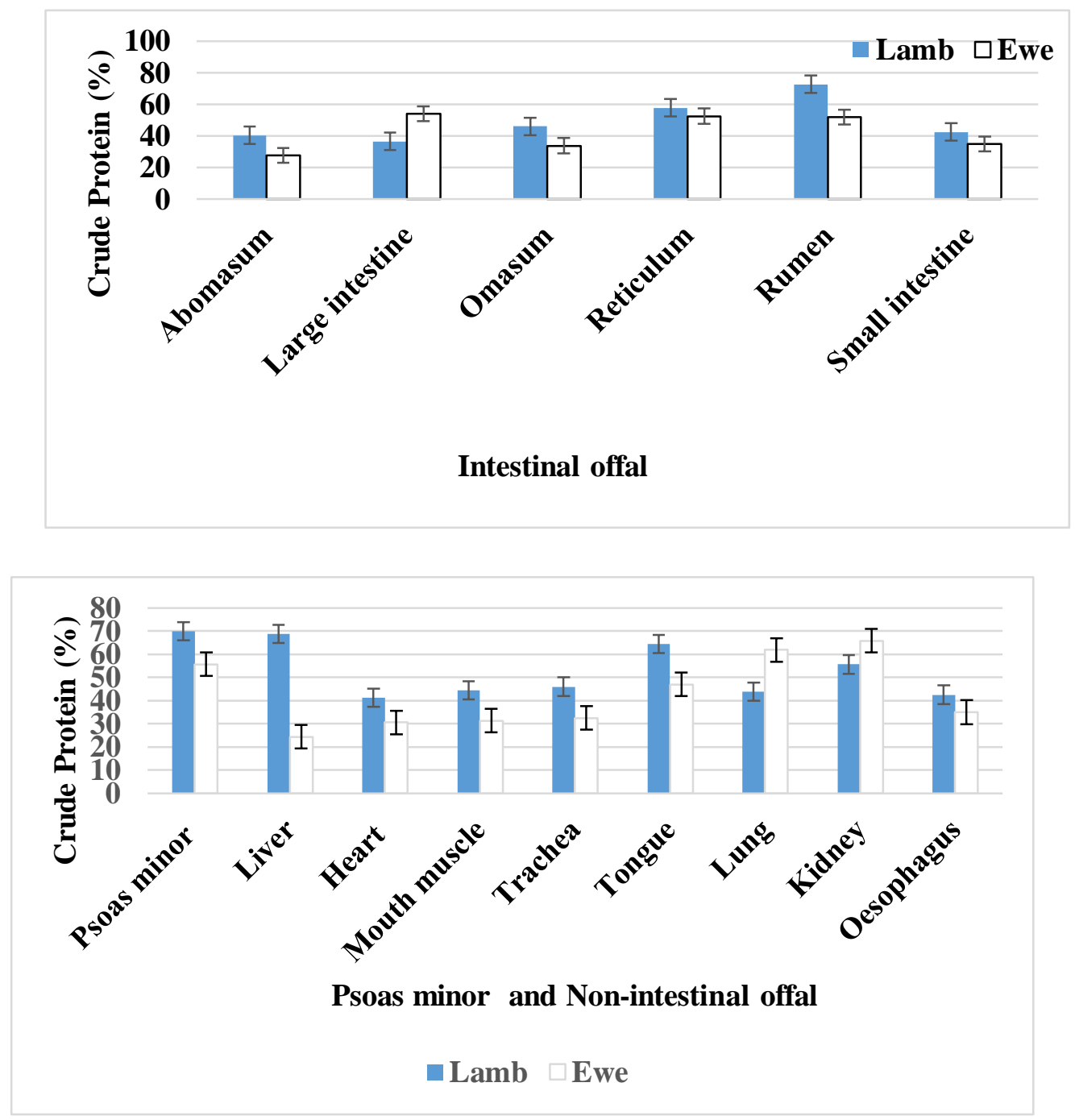

Figure 3 Crude protein contents of edible offal and psoas minor muscle from Dohne Merino lambs and ewes

the sheep, the rumen samples showed the highest degree of inflexibility against thermal treatment during sous vide cooking. The presence of the thick papillary muscle, ruminal pillars and sacs (namely, the cranial sac and ventral sac) might have restricted the water activity during cooking. A variation in tenderness for the rumen from lambs and ewes was not feasible since the thickness of the network formed by these muscular sacs was comparable. On the contrary, the inequality between the WBSF values of the reticulum from the lambs and older sheep suggested that the thickness of their mucosal layers and folds of tunica muscularis was not the same owing to age and physiologic differences. Since the thickness of the reticular walls develops with age, it is logical to relate the peculiarity in thickness of the inner oblique, middle circular and outer longitudinal layers of the reticulum to the age at which the lambs and ewes were slaughtered. The breed of the animal (Greiner et al., 2003), the age at slaughter (Tateo et al., 2008), the type of muscle that was cooked (Obuz \& Dikeman, 2003), and the amount of intramuscular fat and the length of sarcomere (Kemp et al., 2010) are other factors that contributed to the WBSF values.

Surface orientation or food microstructure is important in designing new products. Spatial arrangements and interrelationships between similar and dissimilar elements in food are vital to understand the physicochemical, technological and functional properties of food (Aguilera \& Stanley, 1999). Intrinsically, most meat samples examined under SEM displayed an anisotropic orientation, which was similar to activated muscular tissues in which most of the skeletal muscle fibres from the fascicle cross-sections were packed into bundles of anisotropic fibres (Van Doorn et al., 1996; Kocks, 2000; Anderhalt, 2007). Several factors have been ascribed to the kinds of results obtained in the current investigation. The effect of excitation energy on molecular weight, binding state, viscosity, alignment between excitation and emission dipoles of meat samples influence those surface orientations that were observed under SEM (Kocks, 2000; 
Ling et al., 2013). While imaging high-contrast fluorescent protein, Sharafi \& Blemker (2010) found rotational mobility (size) and the fluorescence lifetime of the protein were responsible for an anisotropic orientation. In their findings, Rizzo \& Piston (2005) associated an anisotropic alignment with nutrient density, heat capacity, conductivity, textural patterns and peculiarities of the fusiform muscles in some muscle fibres. As opposed to anisotropy, the surface orientation in the small intestine, psoas minor, lung and mouth muscle showed a form of isotropic alignment. The circular isotropic orientation observed from the lungs of Dohne Merino sheep describes the typical kind of isotropy that is expected from the cardiac muscle. Nonetheless, a number of shapes such as flat bands, spindle shapes and even large protrusions have been detected from skeletal muscles through an SEM (Martini et al., 2008). A concentric shape such as that displayed by the lung describes a different way in which samples with isotropic orientation can align around an opening or recess (Cao et al., 2010). The oblique pattern of short fibres with the circular shape of the visceral layer shows the presence of inner pleura linings, outer parietal layer and clusters of microscopic air sacs (alveoli) (Gaige, 2007; Martini et al., 2008). Each meat sample has its unique elemental map and nutrient composition. The nitrogen levels in the rumen, psoas minor and liver from the lambs were the highest among the meat samples. These amounts translated to a maximum crude protein contents of $72.5 \%$ from the rumen, $70 \%$ from the psoas muscle and $68.8 \%$ from the liver. The protein contents in these meat samples are indicators of their amino acid composition, flavour, physiochemical properties and nutritional quality.

\section{Conclusion}

The findings from this study established strong interrelationships between surface orientation, cooking temperature, timing and tenderness of the edible offal and psoas minor muscle from Dhone Merino lambs and ewes. It is evident that each anatomical part requires an appropriate mechanical force for shearing and that sous vide apparatus produced the tenderest meat from cooking at $100{ }^{\circ} \mathrm{C}$ for 30 minutes. Admittedly, disparities in the ages and sex of the animals significantly influenced the tenderness of most meat samples under different cooking temperatures and durations. By using SEM to characterize the surface orientation, it was possible to generate surfaces with high resolution and predict the elemental composition of various meat samples. SEM made it easier to classify and describe the surface orientations and elemental compositions of edible offal and psoas minor muscles through energy dispersive $\mathrm{X}$ - and surface morphologies.

\section{Acknowledgements}

The authors are grateful to Govan Mbeki Research and Development Centre (GMRDC), Red Meat Research and Development (RMRD-SA) and National Research Foundation (NRF) of South Africa (Projects T079 and THRIP T113) for funding this study. Thanks to the management of the East London abattoir for their cooperation during data collection. We equally appreciate the technical support from McMillan B., Sibanga M. W.,Pepe D. and Nyanga, M. in the process of data gathering.

\section{Conflict of Interest Declaration}

The authors declare that they have no conflict of interest.

\section{Authors' Contributions}

The work was designed by FPO and VM. FPO collected the data, did the analysis and wrote the manuscript. Both authors read and approved the final draft of the manuscript.

\section{References}

AGFACTS, 2003. How to tell the age of sheep. New South Wales Department of Agriculture. Available at: https://www.dpi.nsw.gov.au/_data/assets/pdf_file/0004/179797/aging-sheep.pdf

Aguilera, J.M. \& Stanley, D.W., 1999. Microstructural Principles of Food Processing and Engineering. 2nd edition. Aspen, Maryland.

American Meat Science Association, 1995. Research guidelines for cookery, sensory evaluation and instrumental tenderness measurements of fresh meat. American Meat Science Association in cooperation with National Livestock and Meat Board. American Meat Sci. Ass. pp. 1-47.

Anderhalt, R., 2007. X-ray Microanalysis in Nano-Materials. Scanning Microscopy for Nanotechnology, Techniques and Applications, Springer, 76-100.

Ayadi, M.A., Makni, I. \& Attia, H., 2009. Thermal diffusivities and influence of cooking time on textural, microbiological and sensory characteristics of turkey meat prepared products. Food Bioprod. Proc. 8, 7327-7333.

Badwin, D.E., 2011. Sous vide cooking: A review. Int. J. Gastro. Food Sci. 1, 15-30.

Belskie, K.M., Van Buiten, C.B., Ramanathan, R. \& Mancini, R.A., 2015. Reverse electron transport effects on NADH formation and metmyoglobin reduction. Meat Sci. 105, 89-92.

Bozzola, J.J. \& Russel, L.D., 1999. Electron Microscopy: Principles and Techniques for Biologists. Jones \& Barlett, Sudbury, MA. pp. 48-71. 
Cao, H., Li, Q., Hui, Z. \& Jianjiang, C., 2010. Exposure and risk assessment for aluminium and heavy metals in Puerh tea. Sci. Total Env. 408, 2777-2784.

Charge, S.B. \& Rudnicki, M.A., 2004. Cellular and molecular regulation of muscle regeneration. Physical Rev. 84, 209-238.

Chiavaro, E., Rinaldi, M., Vittadini, E. \& Barbanti, D., 2009. Cooking of pork longissimus dorsi at different temperature and relative humidity values: Effects on selected physico-chemical properties. J. Food Eng. 93, 158-165.

Church, I.J. \& Parsons, A.L., 2000. The sensory quality of chicken and potato products prepared using cook-chill and sous vide methods. Int. J. Food Sci. Technol. 35, 155-162.

Cloete, J.J.E. Cloete, L.C. \& Hoffman, S.W.P., 2008. Carcass characteristics and meat quality of progeny of five Merino dam lines, crossed with Dormer and Suffolk sires. S. Afr. J. Anim. Sci. 38, 355-366.

Combes, S, J., Lepetit, B. \& Lebas, D.F., 2003. Effects of cooking temperature and cooking time on Warner-Bratzler tenderness measurement and collagen content in rabbit meat. Meat Sci. 66, 91-96.

Commission International de I'Eclairag, 1976. Colorimetry. Second edition. CIE, Vienna.

Douglas, E.B., 2012. Sous vide cooking: A review. Int. J. Gastro. Food Sci. 1, 15-30.

Egerton, R.F., 2005. Physical principles of electron microscopy: An introduction to TEM, SEM, and AEM. Springer International Publishing, Switzerland. pp. 202.

Erasmus, S.W. \& Hoffman, L.C., 2017. What is meat in South Africa? Anim. Front. 7, 71-75.

Fayemi, P.O. \& Muchenje, V., 2012. Meat in African context: From history to science. Afric. J. Biotech. 11 (6), 1298-1306.

Fayemi, P.O. \& Muchenje, V., 2018. Expression of ovine ubiquitin C-terminal hydroxylase 1, pH and colour of variety meats from head-stunned Dohne Merino sheep. S. Afr. J. Anim. Sci. 48, 88-97.

Fayemi, P.O., Muchenje, V., Yetim, H. \& Ahhmed, A., 2018. Targeting the pains of food insecurity and malnutrition among internally displaced persons with nutrient synergy and analgesics in organ meat. Food Res. Int. 104, 48-58.

Gaige, T.A., 2007. Complex muscle architecture described with diffusion weighted MRI. Massachusetts Institute of Technology. J. Biomedic. Optics, 13, 1-9.

Garcia, P.T., Casal, J.J., Fianuchi, S., Magaldi, J.J., Rodriguez, F.J. \& Ñancucheo, J.A., 2008. Conjugated linoleic acid (CLA) and polyunsaturated fatty acids in muscle lipids of lambs from the Patagonian area of Argentina. Meat Sci. 79, 541-548.

Garcı'a-Linares, M.C., Gonzalez-Fandos, E., Garci'a-Ferna' ndez, M.C. \& Garci'a-Arias, M.T., 2004. Microbiological and nutritional quality of sous vide over traditionally processed fish: Influence of fat content. J. Food Qual. 27, 371-387.

Greiner, S.P., Duckett, S.K. \& Notter, D.R., 2003. Effect of breed type on shear force, sensory analyses and fatty acid content of lamb. J. Anim. Sci. 81 (Suppl.1), 124.

Hayat, M.A., 2000. Principles and Techniques of Electron Microscopy: Biological Applications. Cambridge University Press, New York.

Hong, G.E., Kim, J.H., Ahn, S.J. \& Lee, C.H., 2015. Changes in meat quality characteristics of the sous-vide cooked chicken breast during refrigerated storage. Korean J. Food Sci. Anim. Res. 35 (6), 757-764.

Hopkins, D.L., Stanley, D.F., Martin, L.C., Toohey, E.S. \& Gilmour, A.R., 2007. Genotype and age effects on sheep meat production. 3. Meat quality. Austr. J. Exper. Agric. 47, 1151-1164.

Hosahalli, R. \& Michélc, M., 2006. Food Processing: Principles and Applications. CRC Press, Taylor \& Francis Group, Singapore. p. 169.

Jeremiah, L.E., Tong, A.K.W. \& Gibson, L.L., 1999. The influence of lamb chronological age, slaughter weight, and gender. Flavour and texture profiles. Food Res. Int. 31 (3), 227-242.

Kakarala, A., Banitalebi, H., Borthne, A.S. \& Pierre-Jerome, C. 2016. MRI of the psoas major muscle: Origin, attachment, anatomical variants and correlation with the lumbar disc extrusion. J. Advanc. Rad. Medic. Imag. 1 (2),1-8.

Karel, M. \& Lund, D.B., 2003. Physical Principles of Food Preservation. Second edition, revised and expanded. Marcel Dekker, Inc, New York-Basel. pp. 1-570.

Kemp, C.M., Sensky, P.L., Bardsley, R.G., Buttery, P.J. \& Parr, T., 2010. Tenderness - An enzymatic view (review). Meat Sci. 84, 248-256.

Kocks, U.F. 2000. In: Texture and Anisotropy: Preferred orientations in polycrystals and their effect on materials properties. Cambridge University Press, Technology \& Engineering. pp. 688.

Li, C., Wang, D., Dong, H., Xu, W, Gao, F., Zhou, G. \& Zhang, M., 2012. Effects of different cooking regimes on the microstructure and tenderness of duck breast muscle. J. Sci. Food Agric. Doi: 10.1002/jsfa.6003.

Ling, S., Chen, B., Zhou, Y., Yang, W.Z., Zhao, Y, Q., Wang, L. \& Zheng, Y.P., 2013. An efficient framework for estimation of muscle fibre orientation using ultrasonography. BioMedical Eng. Online 12 (98), 1-17.

Martini, F.H., Timmons, M.J. \& Tallitsch, R.B., 2008. In: Human Anatomy. 6th edition. Benjamin Cummings Publishing, Toledo, OH, USA. pp. 251-252.

Obuz, E. \& Dikeman, M.E., 2003. Effects of cooking beef muscles from frozen or thawed states on cooking traits and palatability. Meat Sci. 65, 993-997.

O'Quinn, T.G., Legako, J.F., Brooks, J.C. \& Miller, M.F., 2018. Evaluation of the contribution of tenderness, juiciness and flavour to the overall consumer beef eating experience. Trans. Anim. Sci. 2 (1), 26-36.

Protas, M., Voin,V., Wang, J.M.H., Iwanaga, J., Loukas, M. \& Tubbs, R.S., 2017. A rare case of double-headed psoas minor muscle with review of its known variants. Cureus Doi: 10.7759/cureus.1312.

Pulgar, J.S., Gázquez, A. \& Ruiz-Carrascal, J., 2012. Physico-chemical, textural and structural characteristics of sousvide cooked pork cheeks as affected by vacuum, cooking temperature, and cooking time. Meat Sci. 90, 828-835. 
Purslow, P.P., 2005. Intramuscular connective tissue and its role in meat quality. Meat Sci. 70, 435-447.

Rizzo, M.A. \& Piston, D.W., 2005. High-contrast imaging of fluorescent protein FRET by fluorescence polarization. Micros Bio. J. 88, 4-6.

Seong, P.N., Park, K.M., Cho, S.H., Kang, S.M., Kang, G.H., Park, B.Y., Moon, S.S. \& Ba, H.V., 2014. Characterization of edible pork by-products by means of yield and nutritional composition. Korean J. Food. Sci. Anim. Res. 34, 297-306.

Sharafi, B. \& Blemker, S.S., 2010. A micro-mechanical model of skeletal muscle to explore the effects and fascicle geometry. J. Biomech. 43, 3207-3213.

Shen, X., Zhang, M., Bhandari, B. \& Gao, Z., 2018. Novel technologies in utilization of by-products of animal food processing: A review. Crit. Rev. Food Sci. Nutr. 4, 1-11.

Shirima, E.J.M., Mtenga, L.A., Kimambo, A.E., Laswai, G.H., Mgheni, D.M., Mushi, D.E., Shija, D.S., Safari, J.G. \& Hozza, W.A., 2013. Effects of days in feedlot on physico-chemical properties and meat tenderness from Tanzanian Long Fat-Tailed Sheep. J. Anim. Prod. Adv. 3 (2), 40-48.

Swanepoel, J.W., Van Wyk, J.B., Cloete, S.W.P. \& Delport, G.J., 2007. Inbreeding in the Dohne Merino breed in South Africa. S. Afr. J. Anim. Sci. 37, 176-179.

Tateo, A., De Palo, P., Ceci, E. \& Centoducati, P., 2008. Physicochemical properties of meat of Italian heavy draft horses slaughtered at the age of eleven months. J. Anim. Sci. 86, 1205-1214.

Toldra, F., Mora L. \& Reig, M., 2016. New insights into meat by-product utilization. Meat Sci. 120, 54-59.

Valentin, S., Yeates, T.D., Licka, T. \& Elliott, J., 2016. In vivo MRI features of spinal muscles in the ovine model. J. Orthop. Translat. 6, 1-9.

Van Doorn, A., 1995. Muscle fibre orientation determined by magnetic resonance diffusion tensor imaging. Cip-data Koninklijke Bibliotheek, Den Haag. pp. 1-76.

Von Seggern, D.D., Calkins, C.R., Johnson, D.D., Brickler, J.E. \& Gwartney, B.L., 2005. Muscle profiling: Characterizing the muscles of the beef chuck and round. Meat Sci. 71, 39-51.

Walsh, H., Martins, S., O' Neill, E.E., Kerry, J.P., Kenny, T. \& Ward, P., 2010. The effects of different cooking regimes on the cook yield and tenderness of non-injected and injection enhanced forequarter beef muscles. Meat Sci. 84, 444-448.

Warner, R.D., Pethick, D.W., Greenwood, P.L., Ponnampalam, E.N., Banks, R.G. \& Hopkins, D.L., 2007. Unravelling the complex interactions between genetics, animal age and nutrition as they impact on tissue deposition, muscle characteristics and quality of Australian sheep meat. Austr. J. Exper. Agric. 47, 1229-1238.

Xia, J.J., Berg, E.P., Lee, J.W. \& Yao, G., 2010. Characterizing beef muscles with optical scattering and absorption coefficients in VIS-NIR region. Meat Sci. 75, 78-83. 